\title{
Optimizing Drug Supply Chain in Hospital Pharmacy Department: An Empirical Evidence from a Developing Country
}

\author{
John Mensah (corresponding Author) \\ School of Business, Cape Coast Polytechnic, P.O. Box AD 50, Cape Coast
}

Tel: 233-202-998-102 E-mail: jmjohnmensah@gmail.com0

Dr Jonathan Annan

School of Business, Kwame Nkrumah University of Science and Technology

Tel: 233-202-508-605 E-mail: jothananan.ksb@knust.edu.gh

Dr David Asamoah

School of Business, Kwame Nkrumah University of Science and Technology

Tel: 233-203-504-444Ｅ-mail: asamoahdavid20@gmail.com

Received: June 11, 2015 Accepted: July 4, 2015

doi:10.5296/ber.v5i2.7789

URL: http://dx.doi.org/10.5296/ber.v5i2.7789

\begin{abstract}
Healthcare organisations all over the world are looking for ways to improve operational efficiencies at reduced costs without affecting their services. This study was undertaken to first and foremost examine the supply chain practices at KATH Pharmacy, and secondly to assess those practices in the light of industrially accepted best practices. Primary data was obtained from fifty-five (55) respondents and the data were analysed using SPSS, and queuing model. Interesting findings emerged from the study, including patients spending an average of 12 minutes within the system of drug dispensing unit. However, this time can be reduced if the numbers of servers within the facility is increased by way of opening more dispensing outlets.
\end{abstract}


Keywords: Supply Chain, Drugs, Pharmacy, Procurement

\section{Introduction}

Health care organisations all over the world are looking for ways to improve operational efficiencies and reduce costs without affecting patients care and services. Material requirements for healthcare delivery are numerous, creating a complex supply network of relationships from the supplier to the customer. Meanwhile, "Health care budgets are very tight generally, and that is why health providers worldwide are striving to improve processes and reduce costs" (NHS, 2004).

A supply chain consists of all stages involved, either directly or indirectly, in fulfilling a customer request. A supply chain includes manufacturer, supplier, transporters, warehouses, retailer, third-party logistics provider, and customer. Supply chain management aims to maximize the overall value generated rather than profit generated in a particular supply chain (Chopra, and Meindl, 2001).

The pharmaceutical supply chain provides the means through which prescription medicines are delivered to patients. Pharmaceuticals are produced in manufacturing sites; are transferred to wholesale distributors; stocked at retail, mail-order, and other types of pharmacies; subject to price negotiations and processed through quality and utilization management screens by pharmacy benefit management companies (PBMs); dispensed by pharmacies; and ultimately delivered to and taken by patients (Kaiser, 2005).

The pharmaceutical supply system is complex, and involves multiple organizations that play differing but sometimes overlapping roles in drug distribution and contracting. Price variability across different types of consumers is a common phenomenon due to the level of complexity. This makes it difficult for policy makers to analyse and understand this supply chain. Increased understanding of these issues on the part of policymakers should assist in making rational policy decisions for the Medicare and Medicaid programs (Kaiser, 2005).

An inefficient supply chain is associated with product discontinuity, product shortages, poor performance, lowered patient safety, dispensing errors and technological errors causing stock shortages in pharmacies (WHO, 2008). Increasing the efficiency of Supply chain processes can contribute to building up of a smarter, safer and lower cost of pharmacy operations in Public Hospitals Medicines Management Unit, by optimizing the supply processes, reducing errors, improving patient safety and satisfaction (Squire, Jr. 2008).

Supply Chain Integration which refers to seamless collaboration among supply chain partners, has been considered as a means to reduce operations costs and supply chain inefficiencies, as well as improving the service level in a pharmacy department. Ineffective supply chain management processes and integration in the Komfo Anokye Teaching Hospital (KATH) Pharmacy operations gives much to be concerned as it portrays as the hospital is being left in the dark. This, if not rectified will result in operational inefficiencies and hinder the ability to adequately meet the drug demands of patients in such a Teaching hospital which is the second largest hospital in the country. 
The pharmacies of large hospitals, such as KATH serves a large number of people from far and near. These hospitals, due to their sizes are able to provide a wide range of pharmaceutical products including specialist drugs that are unlikely to be sold in ordinary local pharmacies. Also, the expertise of the staff (pharmacists) in such pharmacies makes them attractive to most patients especially in this era where fake drugs are rampant in societies. To be able to serve effectively this large number of people without room for delays and stockouts, the procurement of pharmaceuticals, systems for quantification of drugs and inventory management systems must be highly effective. There is also the need to upgrade the skills of trained staff in implementing standard operating procedures prepared for the management of medicines, supplies and equipment.

However, a comprehensive distribution arrangement to move pharmaceutical products and other medical supplies from the medical stores to the service points is lacking and as such has become a major bottleneck to access to these items (GNDP, 2004). To solve the above problem, there is the need for the building of a smarter, safer and lower cost of pharmacy operations on achieving optimal availability and use of drugs based on effective supply chain processes.

The aim of the study is to identify operational supply chain activities of the Pharmacy department of KATH, evaluate those practices in the light of the eight key supply chain processes, and how KATH is integrating these processes into its own supply chain processes and finally make recommendations on how to improve these processes. The subsequent sections of this paper is organised as follows: section two presents a review of relevant literature on drug supply chains and optimisations strategies together with other relevant considerations to the subject matter. Next, the methods used in gathering data and conducting our analysis is presented. We then present the results obtained from the data gathered and our discussion of the findings in the next section. Finally, we provide a summary of our findings, conclusion and recommend specific courses of action that can improve the supply chain of drugs in our chosen unit of study.

\section{Literature Review}

\subsection{Supply Chain Management}

According to the Global Supply Chain Forum, SCM is 'the integration of key business processes from end user through original suppliers that provide products, services, and information that add value for customer and other stakeholder' (Chan \& Qi, 2003). Supply Chain Management is about measures to transform the supply chain of a firm into an optimally efficient, customer-satisfying process, where priority is given to total supply chain effectiveness over the effectiveness of individual components. (Deveshwar \& Rathee, 2010). The goal of SCM is for members in the organisations to integrate, work together, and build a partnership with each other (Mentzer et al., 2001).

\subsection{Medicines Supply Chain}

According to Romero, (2013), the supply chain management in the healthcare system is being characterized "by the information, goods and money essential to purchase and transfer the 
goods and services from the supplier to the final user in order to control costs" (Schneller, Smeltzer, and Burns, 2006). In terms of projection, the healthcare supply chain management is always rated to spend hundreds of millions of dollars per year (Ontario Buys \& Healthcare Supply Network, 2007), which suggests that hospital financial primacies must be re-defined. The healthcare supply chains are more composite and more unformed related to other industries [(Schneller, Smeltzer, and Burns, 2006; Langabeer, 2007; Mustaffa, and Potter, 2009). This can be explained by different reasons. First, supply chain management has an impact on human health requiring adequate and accurate medical supply conforming to the patients' needs (Beier, 1995). If medical supplies are out-of stock, distributed to the wrong patient or are prepared inadequately, patients may experience adverse events, and in some cases death (Boulet, 2001 ;Shaeffer, 2009). In fact, it is estimated that one million medication errors occur each year in U.S. (Kuperman, Bobb, and Payne, 2007) accounting for 7,000 deaths and entailing a cost of about $\$ 2$ billion a year (Kohn, L., Corrigan, J., and Donaldson, M., 2000). Again, medical products, medicines and equipment are not totally consistent. Professionals in the industry are responsible for their selection, but their choice depends on the physical characteristics and health status of each patient (Schneller, Smeltzer, and Burns, 2006). Certainly, they can request different kinds of products for patients undergoing the same treatment. Accordingly, several products, medicines and equipment are required, resulting in differentiated and complex health services and generating negative impacts on the hospital finances (Schneller, Smeltzer, and Burns, 2006). More so, hospital operations must deal with a multifaceted distribution network composed of several storerooms and warehouses where different medical supplies are stored following a variety of regulations (Rivard-Royer, Landry, and Beaulieu, 2002).

\subsection{Responsive Supply Chain}

The supply chain for pharmaceutical products is complex, and involves multiple organizations that play differing but sometimes overlapping roles in drug distribution and contracting (Kaiser, 2005). An inefficient supply chain is associated with product discontinuity, product shortages, poor performance, lowered patient safety (WHO, 2008). Increasing the efficiency of Supply chain processes can contribute to building up of a smarter, safer and lower cost of pharmacy operations by optimizing the supply processes, reducing errors, improving patient safety and satisfaction (Squire, Jr. 2008). According to Fisher, (1997) the purpose of responsive supply chain is to react quickly to match the demand of the market. From Kaiser (2005), Producers are the source of prescription drugs in the pharmaceutical supply chain. Wholesale distributors purchase pharmaceutical products from producers and distribute them to a variety of customers, including pharmacies (retail and mail-order), hospitals, and long-term care and other medical facilities (e.g., community clinics, physician offices and diagnostic labs). Research by the Kaiser (2005), revealed that Pharmacies are the final step on the pharmaceutical supply chain before drugs reach the consumer/patient. Lambert et al. perceive a two way flow of information. Basu and Wright (2008) complement to physical flow of goods and flow of information, the flow of funds to some supply chain such as those found with point of sale or retail operations. According to Milliet (2003), it is more profitable to abide by the rules and regulations connected with pharmaceutical 
distribution. With respect to responsive supply chain Fisher, (1997) revealed that the objective is to be respond quickly to unpredictable demand in order to minimise stockout, forced markdowns and obsolete inventory. Again companies must work aggressively to reduce their lead time as long as it doesn't increase their cost and generate high turns and minimise inventory throughout the chain.

\subsection{Supply Chain Collaboration}

With regard to the work of Betts, and Tadisina, (2009), Supply chain collaboration is often defined as "two or more chain members working together to create a competitive advantage through sharing information, making joint decisions, and sharing benefits which result from greater profitability of satisfying end customer needs than acting alone". We can measure the degree of collaboration in relationships by looking at 1) how companies interact with each other and 2) the means by which they interact. Under the first category are elements like trust and commitment, the balance of power and how cultural differences among partners are worked out. Under the second category are information systems and a collaborative controlling system, which includes a "reward and risk sharing structure," a "joint decision making system" and a "conflict management system."

Whipple and Russell (2007) identified three "types" of collaboration. Type I - collaborative transaction management; Type II - collaborative event management; and, Type III collaborative process management. Whipple and Russell (2007) posit that the number of collaborative relationships will decrease as the Type increases from I to III. Additionally, they posit that the sustainable payoffs from collaborative relationships will increase as the Type increases. In other words, these authors predict there will be more of a sustainable payoff from a Type III collaborative relationship than a Type I. The "types" identified by Whipple and Russell (2007) are progressive.

\subsection{Supply Chain Dissection}

According to Ebel, T., Larsen, E., and Shah, K., (2013), many pharmaceutical and medical-device companies come close to running one-size-fits-all supply chains. In practice, however, there can be significant differences in profitability, value per unit of weight, demand, the importance of a drug or device to patients, a customer's cost to serve, and service expectations. Forcing products with such varied characteristics through a single set of supply-chain processes creates multiple inefficiencies, such as high inventories for some products while others are in short supply, the use of expensive air freight when slower surface modes would do, or a need to reschedule production campaigns hastily to meet urgent delivery requirements. Leading companies tackle these problems by intelligently segmenting their supply chains according to the characteristics of products and the requirements of customers. They then develop forecasting, production, and distribution strategies for each category.

\subsection{Inefficiencies in Supply Chain}

Most of the studies done shows that, pharmacy logistics processes are related to several issues that impact negatively on the cost and quality of the medication services. For instance, 
out-of-stock (Danas, Ketikidis and Roudsari, 2002; West, 2003; Breen, and Crawford, 2004; Dongsoo, 2005), high costs (West, 2002), excessive manual labour (Rosseti et al., 2008; Dreyer et al., 2010), shrinkage (Danas, Ketikidis and Roudsari, 2002, Rosseti et al., 2008; Vila-Parrish, Ivy, and King, 2008), high frequency of reorders (Danas, Ketikidis and Roudsari, 2002, Rosseti et al., 2008), counterfeit products (Schuster, Allen, and Brock, 2007; Basta, 2008; Lefebvre, 2011) and product recalls (Schuster, Allen, and Brock, 2007) shows different inefficiencies in the pharmacy supply chain. Inefficient supply chain management also results in late deliveries and large stockouts. Fundamentally, these effects are caused due to an inability of the firm to predict the requirement for raw material and equipment capacity together with the uncertainty associated with obtaining deliveries of products on time from its suppliers (Swaminathan, 2000). Fisher et. al. (1994) described how accurate forecasts in the apparel industry could potentially reduce this inefficiency.

\subsection{Improving the efficiency of Pharmacy Supply Chain function}

This is an indispensable option for ensuring the profitability of the healthcare organizations. Past research work shows that hospital pharmacy can adopt several managerial approaches such as Just-In-Time (Danas, Ketikidis and Roudsari, 2002; Breen, and Crawford, 2004), Virtual Inventory (Danas, Ketikidis and Roudsari, 2002), Stockless Materials Management Programs or Vendor Managed Replenishment (VMR) (Landry, and Philippe, 2004; Chandra, 2008), Collaborative Planning, Forecasting and Replenishment (CPFR) [Breen, and Crawford, 2004; Dreyer, 2010, Chandra, 2008], simulation and outsourcing (Rosseti, 2008). These managerial transformations must be supported by information technologies, namely Exchange Data Interchange (EDI) (Danas, Ketikidis and Roudsari, 2002; Breen, and Crawford, 2004; Dreyer, 2010), e-commerce [Breen, and Crawford, 2004; Dreyer, 2010; Chandra, 2008), barcode and RFID (Bussières, and Lebel, 2004; Jones et al., 2010).

\subsection{Conclusion}

Current drug supply chain management is characterized by parallel processes and information systems that result in poor quality and inefficiencies. Less than expected health system performance, stock outs and other shortages affect drug supply and primary care in the general hospital. Poor performance of supply chain management is amplified by weak conditions at all levels of the health system, including the areas of financing, governance, human resources and information. Governance issues include the lack to follow up initial policy intentions and a focus on narrow, short-term approaches.

\section{Research Methodology}

KATH in recent times has undertaken a review process programme in order to improve their medical services to the people in the Northern Sector of the country and some neighbouring countries. KATH Pharmacy department represents the primary research site for the data collection, simply because of its position and the quantity of different pharmaceutical products, which are received, stored and distributed to numerous clients. KATH is also in the process of reviewing their pharmacy processes in order to regulate their activities and ensure a future partnership with some of its suppliers. Primary data was obtained using personal 
observations, formal and informal interviews with management of the Pharmacy department and some of the units under the department. The use of different methods of data collection in a single study is justified because triangulation has proven effective in establishing reliability and validity in many studies (Romero, 2013), and again consultation was made with professional executives in the purchasing and supply field. Secondary data was obtained from books, journals, the internet and websites of some relevant government institutions such as Ghana Health Service. In all, Fifty-five (55) respondents, made up of management members and staff of the pharmacy Department of KATH were used for the study. The Pharmacy under the Directorate of Pharmacy comprises: Medicines Management Unit, Drug Information Unit, Manufacturing Unit and Specialist OPD Pharmacy unit. The background of the respondents showed that $68 \%$ were males. The level of education of all the respondents was Tertiary, of which $51 \%$ are within the ages $31-40$ years, $38 \%$ are also between $41-50$, with $7 \%$ and $4 \%$ are 21-30 and above fifty (50) years respectively. We collected data from members in all levels of the department of interest to prevent elite bias (Miles and Huberman, 1994). The study predominantly employed the quantitative method in the data analysis using SPSS and Microsoft excel 2010 to deeloped simple tables and charts to display responses as well as employing a modelling of a Queuing theory in determining the system utilization of the pharmacy department.

\section{Results and Discussion}

\subsection{Structure of the Section}

Having adopted the concept of triangulation in establishing the validity and reliability of the data collected, we present the results obtained alongside our discussions using a predominantly qualitative method with few instances of quantitative analyses.

In line with the objectives of the study, the data collected were grouped under nine categories namely: drug ordering process, payment systems, mode of communication, inventory system, and responsiveness to KATH demand, strength of supplier relationships and level of technology adopted in operations, mode of drug transportation and supply chain risk factors. The queuing theory was also used to estimate the average utilization and the average time patients spend at the pharmacy department. Next, we evaluated the supply chain management practices of the unit in the light of best practices and body of Knowledge.

\subsubsection{Background of Respondents}

\subsection{System Utilization of KATH Pharmacy Department}

This is the ratio or the average of the time that the Pharmacy department is in use to the total time that it could be in use. It is often averaged over time in the definition such that the ratio becomes the amount of capacity used divided by the maximum possible to be used. As per the objective of this study, we collected data to estimate KATH's pharmacy system utilization which seeks to explain the ratio of demand to the supply or capacity of the pharmacy units at the various departments (as measured by the product of the number of servers, $(M)$ and the service rate, $(\mu))$ 


$$
P=\frac{\lambda}{m}
$$

The average number of patients being served:

$$
r=\frac{\lambda}{\mu}
$$

The average number of customers waiting in line for service:

Lq (model dependent obtained using a table or formula)

In the system (line plus being service)

$$
L s=L q+r
$$

The average time patients are:

Waiting in line for drugs:

$$
W q=\frac{L q}{\lambda}
$$

Waiting in the unit:

$$
W s=W q+\frac{1}{\mu}
$$

Concerning the Pharmacy units Utilization at the KATH Pharmacy department, it was observed that patients arrive at an average rate of 60 patients per hour on week day mornings. Each Pharmacist can serve a patient in an average time of five minutes. In all it was also observed that the average time of patients waiting in line to be serve is 6.25 minutes.

Therefore the service time of the pharmacy: $\frac{1}{\mu}=\frac{1}{12}$

Therefore $\mu=12$

$$
r=\frac{\lambda}{\mu}=\frac{60}{12}=5
$$

Given $\mathrm{Lq}=6.25$

Therefore the average time Patients will spend in the unit is

$$
\frac{L q}{\mu}+\frac{1}{\mu}=\frac{6.25}{60}+\frac{1}{12}=0.2 \text { hours or } 12 \text { minutes }
$$


For this time, it could be detrimental to the patients whose condition is serious

$$
\begin{aligned}
& \text { System utilization is, } P=\frac{\lambda}{m \mu} \\
& \text { For } m=2, P=\frac{60}{2(12)}=2.5 \\
& \text { For } m=3, P=\frac{60}{3(12)}=1.7 \\
& \text { For } m=4, P=\frac{60}{4(12)}=1.3
\end{aligned}
$$

Therefore, the utilization factor for the KATH Pharmacy department can be reduced to 1.3. Only if they can set up four outlets for dispensing drugs to the patients. This means that, the increase in the number of servers in the Pharmacy department increases the capacity of the department even though it is capital intensive and additional cost to the hospital. This will also increase the service rate of patients that use the Pharmacy department facilities. Again, if the capacity of the Pharmacy department increases, then the other units within the Pharmacy department will be able to reduce the time used to serve its customers for that matter, patients who visit the various units under the department.

\subsection{Elements of Drug Supply Chain Management Processes at KATH}

\subsubsection{Ordering Of Drugs from Suppliers}

At KATH ordering of drugs is hundred percent (100\%) done by the procurement unit under the Supply Chain Department. The format here is that the Pharmacy department raises the requisition. This is forwarded to the Procurement unit which then invites capable and qualified suppliers through the lay down procedures which conforms to the Ghana Public Procurement Act 663, (2003), and Financial Administration Act 654 (2003). The unit has to abide by this law because the hospital is a Public institution which is also consistent with the work done by Milliet (2003).

\subsubsection{Inventory System at the Pharmacy}

Data gathered revealed that inventory system at KATH pharmacy department is wholly based on the push system. Drugs are ordered from manufactures like Ernest Chemist, Tobinco limited etc by the pharmacy department for use by customers of the hospital in far advance of demand. The Pharmacy department adopted this inventory system for two reasons; firstly, due to the procurement requirements of the hospital and secondly, due to production lead-time of producing drugs. The Pharmacy department tries to get all of its drugs from the beginning of the year and it builds stock that need to be pushes to the patients. This is in consistence with Swaminathan, (2000) and Fisher, (1997) research works, which is in order 
to ensure close to hundred percent $(100 \%)$ product availability, many departments have taken the strategy of keeping a huge inventory in their supply chain. Pharmaceutical products margin is remarkably high at KATH Pharmacy department.

\subsubsection{The Mode of Communication between the Pharmacy and their Suppliers}

The dominant mode of communication between the Pharmacy department at KATH and its suppliers are by mobile phone, e-mails and face -to-face, all accounting for ninety percent (90\%), five percent $(5 \%)$ and five $(5 \%)$ percent respectively. The information flows represent orders of drugs and the common channels used by KATH pharmacy department for their orders. The Mobile phone became the most used mode of communication by KATH Pharmacy department. The flows include information about the price, the delivery and the quality (Schneller, Smeltzer, and Burns, 2006).

\subsubsection{Managing the Suppliers}

Based on the data obtained from our respondents, KATH pharmacy's relationship with its suppliers indicate a transaction management kind of collaboration relationship. With Type I relationship, which is collaborative transaction management; Type II relationship is collaborative event management; and type III relationship, which is collaborative process management. The type I accounted for hundred percent (100\%) from the response received from the various units under study at the pharmacy department. This means that, apart from buying the drugs from these suppliers, there is no other collaborations between the suppliers and the hospital. It is of utmost importance for KATH to improve upon this relationship it has with it suppliers which according to Whipple and Russell (2007) is the weakest type of relationship existing among the various types of collaborations.

\subsubsection{Suppliers Responsiveness to KATH Order}

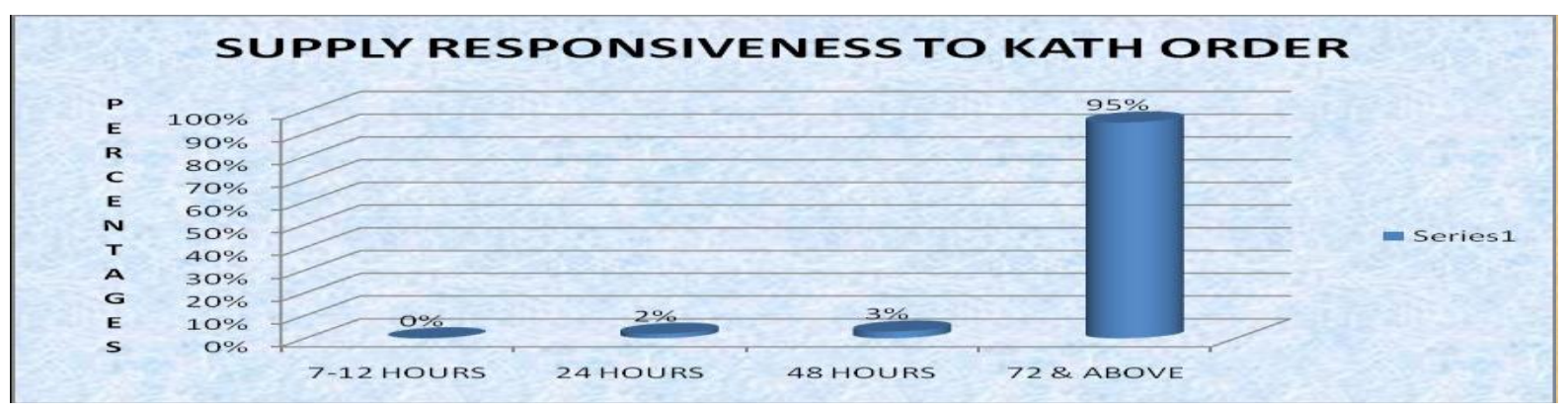

Figure1.

Sources: Author's Field Survey, (2014)

Figure1 indicates that majority of KATH suppliers take almost two days (48 hours) and above to deliver their supplies to the KATH Pharmacy. Any lead time expected within less of this time will be impossible on the part of these suppliers.

The responsiveness of their suppliers can be said to be low which is contrary to the affirmation made by Fisher, (1997). In the case of KATH it is rather too long considering the kind of products involved (drug). Shortage of a critical drug specimen can cause a serious 
problem in the management of health with this lead time they use. This supply chain model would not best suit the environment in which demand predictability is low, forecasting error here can be very high, product life cycle is also very short, new product introductions are the order of the day here. These are the characteristics environment KATH Pharmacy department's found itself. The responsive supply chain design matches competitive priority, emphasizing on quick reaction time, development speed, fast delivery times, customization, and volume flexibility. The prominent design features of responsive supply chains include flexible or intermediate flows, high-capacity cushions, low inventory levels, and short cycle time which all contradict what is going on now at KATH Pharmacy department (Fisher, 1997).

\subsubsection{Payment System at KATH}

In KATH Pharmacy Supply Chain, normally drugs supply by their suppliers are done on credit bases. Sometimes it takes longer than the 91 days to settle creditors. Prompt payment, advance payment and other means are not used at all by the supply chain department at KATH.

\subsubsection{Mode of Operation (Technology Usage)}

The data gathered indicates that KATH pharmacy uses a software for some of it operations, but is specifically for drug inventory management, checking of National Health Insurance scheme (NHIS) records and processing the payment of the drugs by the Patients. This type of software that KATH Pharmacy department uses lacks the sophistication to facilitate effective supply chain management in the pharmacy and in the entire teaching hospital. The automation level of the hospital pharmacy is rather limited only to the pharmacy department compared with other industries. By now, the pharmacy should have had a software application capable of helping the department to deal with plethora of different operational requirements that the pharmacy department is often confronted with.

\subsubsection{Mode of Transportation}

From the supply chain department the only mode of transport for transporting their drugs are through the road trucks especially, within the country. It came out that KATH use road transport for conveyance of all its drugs from the wholesalers and manufactures and it really takes a lot of time for these drugs to get onto the shelf of Pharmacy department.

\section{Discussion of Findings}

Patients can suffer distress and inconvenience if the supply of medicines is disrupted. Increased demand for drug stock can occur for a number of reasons and can cause difficulties in managing the supply chain. Sections and units representing the various parts of the Pharmacy supply chain in KATH and other parts of the continent, regulators and governments should be committed to working more closely to ensure that patients can continue to obtain medicines quickly and conveniently from the pharmacy or dispensing units to which they have been assigned. From the empirical findings, Ernest Chemist, Intravenous Infusion Company Limited and Rock Chemist are the main suppliers of drugs to the KATH hospital but there is 
nothing like long term partnership or collaborative process management between the hospital and it suppliers. Although pharmaceutical standards do not stipulate that organizations buy directly from upstream partners or should sign contracts that allow for long-term planning and sustainable practices, the network should be well integrated. Due to product quality, prompt delivery and rebates, bulk discounts, etc., pharmaceutical companies worldwide collaborate with Hospitals to achieve some of these goals.

In order for a pharmacy department to develop an efficient supply chain management programme, it is a requirement to have a collaborative process management with the various pharmaceuticals, wholesalers or Manufacturers. Some Wholesalers or Manufactures use state-of-the art inventory management technology within their distribution centers, which use bar codes and radio frequency signal to track and assure accurate product filling for customers and this is absent from the supply chain of KATH and other sister hospitals in the region. Some wholesalers or manufacturer also automate dispensing technologies and have extensive interface capabilities that they are able to electronically connect to hospital pharmacy by way of dispensing software, prescription processing computer systems and point-of-sale cash register system. Accomplishing such integration is a major hurdle in most hospitals in our region now but it is an efficient supply chain process that these hospitals has develop or acquire for operations.

Concerning the mode of the communication, it came out that the Pharmacy department makes extensive use of mobile phone, e-mails and face-to-face communication. It is advisable that Manufacturers maintain regular phone or "face to face" contact with their main customers such as KATH to monitor products, identified as in short supply in order to ensure both parties have a good understanding of the supply and demand for particular products. To facilitate communication, each KATH manufacturer has nominated one person to represent the firm at the hospital. It will be resourceful for the hospital to integrate it system with Enterprise Resource Planning (ERP) package.

The most common enabler of information system integration today is the firm's ERP system. ERP systems provide a view of the entire organization, enabling decision makers within each function to have information regarding customer orders, manufacturing plans, work-in-process and finished goods inventories, outbound goods in-transit, purchase orders, inbound goods in-transit, purchased item inventories, and financial and accounting information. ERP systems thus will link the Pharmacy department supply chain processes and facilitate communication and information sharing between the hospital departments. Since the key hospital supply chain processes overlay each of the functional areas, the hospital eventually becomes process oriented rather than functionally oriented once ERP systems are deployed. This visibility of information across the entire hospital will allow for much greater ease in internal process integration (Bernstein, 2005). That is an enterprise-wide ERP system will permit the KATH institutions to use a shared database from which to make product, customer, and supplier decisions according to Bernstein (2005). Information is captured once, reducing data input errors; information is available in real time, eliminating delays throughout the organization as information is shared; and finally, information will be visible throughout the entire institution. All transactions taking place in every department within the 
hospital can be seen and accessed by everyone on the system and this will help cure some of the malfeasances that arises in the course of distributing the drugs. As the KATH moves away from unconnected legacy systems and moves toward the fully integrated ERP system, an institutional-wide cross-functional team should be created to link key processes throughout the institution, and as a process performance is also monitored and improved, the entire institution will become more focused on managing its key supply chain processes in an integrated fashion. For the various risks affecting KATH Pharmacy's supply chain, disruption was the most prominent risk identified in the supply chain activities due to inefficiencies that arise in the system. It is therefore suggested, that caution must be applied in how such risks are addressed, as there are aspects of the product that highlight its uniqueness. At a very basic level, risks in the pharmaceutical supply chain are most at times associated with product discontinuity which can also have adverse effect on the conditions of patients.

\section{Conclusion and Implication}

The pharmaceutical supply chain is the means through which prescription medicines are delivered to patients. Pharmaceuticals originate in manufacturing sites; are transferred to wholesale distributors; stocked at retail, mail order and other types of pharmacies. Not only is a supply chain a target for significant cost reduction, but improvements in supply chain performance is also a central strategy for overall hospital sustainability in a new era of outcomes based reimbursement. Assessing supply chain process leads to identification of problems and opportunities. Having a strategy and measuring key parts are necessary to understand and take control of your supply chain. The study adopted the case study technique using both primary and secondary sources of data. The supply chain processes in the pharmacy were identified and evaluated in the light of best practices and the findings were reported along with discussions and comparisons with relevant past studies. The queuing theory was used to estimate average waiting time a patient spent within the pharmacy facility as well as estimating the level of utilization of the entire facility. Interesting findings emerged from the study, including patients spending an average of 12 minutes within the system of drug dispensing unit. However, this time can be reduce if the numbers of servers within the facility is increase. KATH Ordering of drugs from its suppliers was also found out to be in the form of a push system coupled with public procurement procedure of procuring these drugs which often leads to unnecessary delay of having these drugs at the right place at the right time. The use of mobile phones, emails and meeting the suppliers face-to-face were the modes of communication between the Hospital and its suppliers. Leaving behind the current architecture system (ERP system) of linking their facility with that of their suppliers for them to timely respond to the replenishment needs of the KATH in terms of drugs. Again, KATH is into transactional management relationship with its suppliers instead of creating a collaboration kind of event management relationship. In all, the study has revealed that the supply chain practices in the department of pharmacies in our sub region falls short of the standard required of the best supply Chain practices in teaching hospital's pharmacies and therefore needs to be improved by the above recommendations.

\section{References}


Basta, N., (2008). Product Security Perspective: Protecting the Brand, Pharmaceutical Commerce. Pharmaceutical Commerce website. Available at: http://www.pharmaceutical commerce.com/frontEnd/991serialization_anticounterfeitin_pedigree_RFID_taggants_barcod e. Html

Beier, F. J. (1995). The management of the supply chain for the hospital pharmacies: a focus on inventory management practices, Journal of Business Logistics, 16(2), 153-173.

Bernstein, M. (2005). Raytheon Goes From Traditional Purchasing to an Integrated Supply Chain, World Trade, 18(11), 36-38

Betts, T., \& Tadisina S. K. (2009). Supply Chain Agility, Collaboration, and Performance: How do they Relate? POMS 20th Annual Conference, Orlando, Florida U.S.A.

Boulet, F., (2001). Les erreurs médicamenteuses ou l'épée de Damoclés, Pharmactuel, 34(6), 161-165.

Breen, L., \& Crawford, H. (2004). Improving the pharmaceutical supply chain: Assessing the reality of e-quality through e-commerce application in hospital pharmacy. International Journal of Quality \& Reliability Management, 22(6), 572-590.

Bussières, J. F., \& Lebel, D. (2004). Utilisation des code-barres dans le cadredu circuit du médicament en établissement de santé. Pharmactuel, 42(2), 131-137

Chandra, C. (2008). The case for healthcare supply chain management: insights from problem-solving approaches. International Journal of Procurement Management, 1(3), 261-279.

Cheruiyot, K. P. (2013). Impact of integrated supply chain on performance at Kenya Tea Development Agency. International Journal of Social Sciences and Entrepreneurship , 1(5), 194-203.

Chopra, et al. (2001). Supply Chain Management: Strategy, Planning, and Operation. New Jersey, Prentice Hall, p448 [Accessed on 15 February,2011]

Danas, K., Ketikidis, P., \& Roudsari, A., (2002). A virtual hospital pharmacy inventory: An approach to support unexpected demand. Journal of Medical Marketing: Device, Diagnostic and Pharmacetical Marketing, 2(2), 125-128,

Deveshwar and Rathee (2010). Challenges for Supply Chain Management in Today's Global Competitive Environment, International Review of Business Research Papers, 6(2), 194-203

Dreyer, H., Strandhagen, J., Romsdal, A., \& Hoff, A., (2010). "Principles for Real-time, Integrated Supply Chain Control: an Example from Distribution of Pharmaceuticals. Advances in Production Management Systems. New Challenges, New Approaches, 1, 187-194.

Dongsoo, K. (2005). An integrated supply chain management system: a case study in healthcare sector, in proceedings of the E-commerce and Web Technologies: Sixth International Conference, Copenhagen, Denmark 
Ebel, T., Larsen, E., \& Shah, K., (2013). Strengthening health care's supply chain: A five-step plan, World Congress on Engineering and Computer Science, Vol II, San Francisco, USA

Felix T. S. Chan, H. J. Qi, (2003). An innovative performance measurement method for supply chain management, Supply Chain Management: An International Journal, 8(3), 209-223. http://dx.doi.org/10.1108/13598540310484618

Fisher M. L., J. H. Hammond, Obermeyer, W. R., Raman, A., (1994). Making Supply Meet in an Uncertain World, Harvard Business Review, 72(3), 83-89.

Jalal A., (2007). It is Only Human to have Conflict, The Conflict Resolution and Negotiation Journal, Vol. 2007, Issue 1, pp 1-7 (Basic Research).

Jones, E., Henry, M., Cochran D., \& Frailey, T., (2010). RFID Pharmaceutical Tracking: From Manufacturer through In Vivo Drug Delivery, Journal of Medical Devices, 4, 015001-1-015001.

Kaiser (2005). Follow the Pill: Understanding the US Pharmaceutical Supply Chain. http://www.rila.org/enterprise/retaillitigationcenter/

Kohn, L., Corrigan, J., and Donaldson, M. (2000). To err is human: building a safer health system: National Academy Pr.

Kuperman, G., J., Bobb, A., \& T. H. Payne H. T., (2007). Medication- related Clinical Decision Support in Computerized Provider Order Entry Systems: A Review. Journal American Medicine Informatics Association. 14(1), 29-40.

Landry, S., \& Philippe, R. (2004). How logistics can service healthcare, Supply Chain Forum, 5(2), 24.

Langabeer, J., (2007). Health care operations management: a quantitative approach to business and logistics, Jones \& Bartlett Publishers.

Lefebvre, E., Romero, A., Lefebvre, L-A., \& Krissi, C., (2011). Technological strategies to deal with counterfeit medicines: the European and North-American perspectives", International Journal of Education and Information Technologies, 5(3), 275-284.

Mentzer, J. T., DeWitt, W., Keebler, J. S., Min, S., Nix, N. W., Smith, C. D., \& Zacharia, Z. G. (2001). Defining supply chain management. Journal of Business logistics, 22(2), 1-25.

Mettler and Rohner (2009). E-Procurement in Hospital Pharmacies: An Exploratory.

Miles MB, and Huberman M. (1994). Qualitative Data Analysis: A Sourcebook of New Methods. 2. Beverly Hills, CA: Sage Publications Pp 23-27

Milliet (2003), Pharmaceutical and healthcare, [Online] pharma@ibs.net or visit www.ibs.net Ministry of Health (2010). Essential Medicines List, 6th Edition, Ghana National Drugs Programme (GNDP) ISBN 978-9988-1-2539-4, www.moh-ghana.org/UploadFiles

Mustaffa, H. N., \& Potter, A., (2009). Healthcare supply chain management in Malaysia: a 
case study, Supply Chain Management: An International Journal, 14(3), 234-243.

National Health Policy Forum, (2005). The ABCs of PBMs, Health National Prescription http://www.imshealth.com/ims/portal/front/articleC/0,2777,6599_49695974_68913551,00.ht $\mathrm{ml}$

NHS Purchasing and Supply Agency (February, 2004). The Agency's Role in Delivering eProcurement in the NHS, pages 2-4. Retrieved August 20, 2005, from: http://www.ontariobudget.fin.gov.on.ca

Ontario Buys \& Healthcare Supply Network, (2007). Supply Chain Modernization in Ontario Health Care, Improving Patient Care, Enhancing Service Levels and Reducing Costs: A Report on the ESupply Chain Project. Ontario Ministry of Finance, Toronto, report,

Rivard-Royer, H., Landry, S., \& Beaulieu, M., (2002). Hybrid Stockless: a case study, lessons for Health-care supply chain integration, International Journal of Operations and Production Management, 22(4), 412-424,

Romero, A., (2013). Managing Medicines in the Hospital Pharmacy: Logistics Inefficiencies, Proceedings of the World Congress on Engineering and Computer Science Vol II (WCECS), 23-25 October, 2013, San Francisco, USA

Rosseti, M. D., Marek, D., Prabhu, S., Bhonsle, A., Sharp, S., \& Liu, Y., (2008). Inventory management issues in health care supply chains, Center of innovation in healthcare logistics. Available at: http://cihl.uark.edu/Inventory_Management_Issues_in_Health_Care_Final.pdf

Saunders, M., Lewis, P., \& Thornhill, A. (2012). Research Methods for Business Students. Pearson $6^{\text {th }}$ Ed., New York Squire, Jr. (2008). Strategies for Safer and More Efficient Medication Management [Online] www.cardinalhealth.com/.../hospitals/.v [Accessed on January 5, 2011]

Schneller, E., Smeltzer, L. \& Burns, L., (2006) Strategic management of the health care supply chain. Jossey-Bass, San Francisco, Calif,

Schuster, E., Allen, S., \& Brock, D., (2007). Global RFID: the value of the EPCglobal network for supply chain management: Springer Verlag

Shaeffer, R., (2009). Closing the medication safety loop. Computers in Healthcare, 30(3), 30-32.

Squire, Jr. (2008). Strategies for Safer and More Efficient Medication Management [Online] www.cardinalhealth.com/.../hospitals/.v [Accessed on January 5, 2011]

Vila-Parrish, A. R., Ivy, J. S., \& King, R. E., (2008). A simulation-based approach for inventory modeling of perishable pharmaceuticals. Simulation Conference, 2008. WSC 2008. Winter, pp. 1532-1538

West, D. S. (2003). Purchasing and inventory control, In Jackson, R., Effective Pharmacy Management, (9TH Ed.) National Community of Pharmacists Association, Sec. 17, Alexandria, VA. 
West, D. S. (2002). NCPA, Pharmacia Digest, National Community of Pharmacists Association, Alexandria VA, 2002.

World Health Organization (2008) Summary of the evidence on patient safety: implications for research.

Yin R. K., (2003). Case Study Research: Design and Methods Third Edition, Applied Social Research Methods Series, Volume 5, Sage Publication, International Educational and Professional Publisher, 17. http://faculty.washington.edu/swhiting/pols502/Yin.pdf

\section{Copyright Disclaimer}

Copyright for this article is retained by the author(s), with first publication rights granted to the journal.

This is an open-access article distributed under the terms and conditions of the Creative Commons Attribution license (http://creativecommons.org/licenses/by/3.0/). 